\title{
Les colònies musicals: una oportunitat per al desenvolupament competencial
}

\author{
Diego Calderón Garrido, Josep Gustems Carnicer, \\ Caterina Calderón Garrido
}

Universitat de Barcelona

dcalderon@ub.edu

\begin{abstract}
Resum: Les colònies musicals són una proposta educativa amb identitat pròpia que combina l'educació musical amb la pedagogia de l'oci. En aquest article es descriuen les característiques de les colònies musicals actuals $i$ sassenyalen les diverses competències que s'hi desenvolupen.
\end{abstract}

Paraules clau: colònies musicals, pedagogia musical, oci, lleure

Abstract: Music camps are a distinct educational format that combines music education with leisure. This article describes the features of some current music camps and the various skills that they develop.

Keywords: music camps, music education, leisure, free time

Les colònies musicals se'ns presenten com una proposta educativa musical molt habitual a Catalunya. D’aquesta manera, tant escoles de música com empreses de lleure, passant per diferents administracions públiques, ofereixen espais on la pedagogia de loci es fusiona amb l'educació musical per crear un ambient educatiu en què es reforcen les competències personals i socials dels assistents i se'n milloren les aptituds musicals.

En qualsevol cas, les colònies musicals no són una oferta nova, ja que tenen l'origen a escala estatal al 1967, gràcies a una iniciativa pionera de l'Orfeó Lleidatà i del seu director Lluís Virgili (aquestes primeres colònies encara es realitzen). En aquestes colònies es va buscar un espai en el qual es pogués ensenyar els costums i l'idioma propi de Catalunya mitjançant la interpretació de la música coral. Des de llavors el desenvolupament i la propagació ha estat desigual, adoptant diferents noms, formats, durada, objectius, etc. (Calderón, Gustems i Calderón, 2015).

Per aproximar-nos a les colònies musicals en l'actualitat, podem dir que es tracta d'una activitat que es desenvolupa durant el període estival, en un alberg o similar, on un grup d'alumnes reben classes de música de part de professors qualificats i són guiats en les seves activitats d'oci per monitors de lleure, convivint tots ells durant aquesta estada (Calderón, 2015).

D'aquesta manera, i tenint en compte les característiques descrites, no ens hem de deixar enganyar pels diferents noms que amb objectius eminentment publicitaris obvien en ocasions el substantiu "colònia" en les seves diferents propostes. Per tant, i un cop centrats en aquestes activitats educatives, podem analitzar-les tenint en compte la necessitat dels tres agents educatius que hem inclòs en la definició: alumnat/monitors/professorat, i les característiques contextuals on es relacionen: la convivència en un mateix espai; unes activitats que permeten seguir en contacte amb la música durant l'estiu (Palacios, 1995). La interacció dels elements descrits diferencia les colònies musicals d'altres activitats semblants, com poden ser els cursos de perfeccionament o les trobades orquestrals. 


\section{Anàlisi de les colònies musicals en l'actualitat}

Si ens centrem en la denominació pròpia de les colònies musicals, observem com la terminologia emprada varia molt, ja que usa indistintament paraules com campament, curs, colonia o altres noms que no tenen res a veure amb la descripció d'aquesta activitat. La raó d'aquesta varietat es deu principalment a interessos publicitaris.

Pel que fa a l'antiguitat que tenen les colònies musicals que funcionen en l'actualitat, podem afirmar que la mitjana és de 10 anys, tot i que n'hi ha amb una antiguitat superior als 40 anys, davant d'altres de creació molt recent.

En la majoria de casos l'organització sorgeix de la iniciativa privada, en concret des d'alguna entitat lligada a l'educació musical, la qual es posa en contacte amb una altra entitat dedicada al lleure per a l'organització de les activitats doci que complementin les musicals. Malgrat aquesta generalització, hem de recordar que hi ha colònies organitzades des de l'àmbit públic, com és el cas de les colònies "Lestiu és teu" (Generalitat de Catalunya, Xanascat).

Les colònies musicals ofereixen places per a alumnes d'ambdós sexes amb edats compreses entre els sis i els disset anys, per bé que cadascuna de les colònies estableix les seves pròpies limitacions en aquest sentit. De la mateixa manera, hi ha oferta per a alumnat de qualsevol instrument propi de la música clàssica, moderna, tradicional i flamenc, amb diversos requisits previs respecte al nivell depenent de cada colònia, igual que el cas de l'edat. En qualsevol cas hi ha oferta tant per a alumnes sense experiència prèvia com per a alumnes de grau professional.

Centrant-nos en les activitats musicals que es realitzen, podem generalitzar i afirmar que en totes les colònies trobem activitats musicals col-lectives, les quals es complementen en alguns casos amb classes individuals. Aquest treball musical es palesa en els concerts, ja que aquests són un dels components principals de les colònies. D’aquesta manera, observem com a més del concert final, en el qual participen tots els alumnes amb els seus familiars com a espectadors, és habitual la realització de concerts durant la resta de dies de l'estada, de manera que els mateixos alumnes assumeixen el doble paper d'intèrpret i públic. És habitual també la realització d'un o diversos concerts a càrrec del professorat de cada colònia.

Pel que fa a les activitats de lleure, aquestes estan condicionades a l'espai físic on es duen a terme les colònies, de manera que les excursions $i$ les tardes de piscina conviuen amb els jocs habituals que els monitors de lleure organitzen.

$\mathrm{Si}$ ens centrem en aquest espai on s'organitzen les colònies de música, en la seva pràctica totalitat es tracta d'edificis dissenyats o habilitats per a la realització d'activitats similars, com és el cas d'albergs, cases de colònies o col-legis. En alguns casos la colònia fa servir una combinació d’aquests espais, per exemple classes de música en un col-legi i les activitats d'oci i pernoctació en un alberg. En alguns casos, fins i tot l'activitat es realitza en tendes de campanya habilitades per a tal efecte, encara que això, tal com hem recalcat, no és l'habitual.

Pel que fa a la durada de les colònies, en els últims deu anys hi ha una tendència a reduir-ne

la durada: en l'actualitat és d’entre cinc i quinze dies, amb una mitjana de set dies de durada. De la mateixa manera, les hores diàries de classes de música han baixat progressivament, i en l'actualitat és d'aproximadament cinc hores i mitja (Calderón, Gustems i Calderón, 2014).

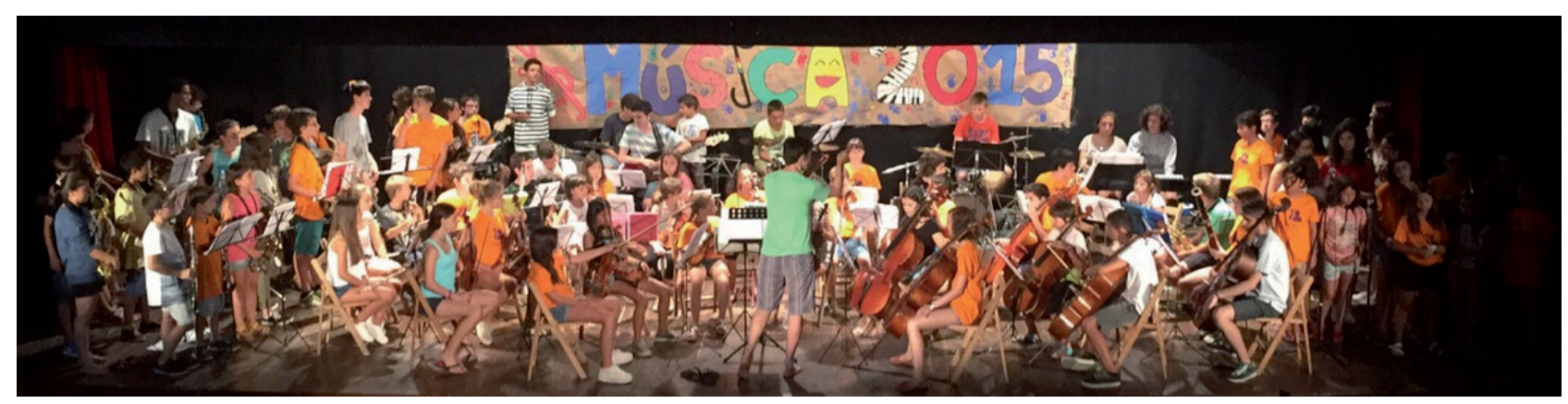


Desenvolupament de les competències en les colònies musicals

Per poder concretar els beneficis de les colònies musicals, hem de conèixer el desenvolupament de les competències que s'hi treballen. Per ferho, tal com descriuen Bisquerra i Pérez, hem d'entendre una competència com "la capacitat de mobilitzar adequadament el conjunt de coneixements, capacitats, habilitats i actituds necessàries per realitzar activitats diverses amb un cert nivell de qualitat i eficàcia” (2007: 63). A més a més d'això, en l'àmbit específic de la música, compartim les paraules de Gustems quan afirma que "l'aprenentatge d'un instrument musical implicarà el desenvolupament de múltiples competències: musicals, corporals, interpersonals, etc." (2007: 7).

Així doncs, el desenvolupament de les competències parteix de la combinació de tots els factors que intervenen en les colònies, és a dir, la música i les activitats guiades de lleure, tenintsempre present la convivència entre els diferents agents educatius. En qualsevol cas, podem classificar les competències que comentem en dos àmbits: d’una banda, l'assimilació i el desenvolupament d'aptituds tecnicoprofessionals (en aquest cas musicals); de l'altra, l’assimilació i el desenvolupament de competències personals i socials.

En qualsevol dels casos, hem de ser conscients de la complementarietat de tots dos àmbits a les colònies musicals, ja que d'aquesta manera s'entén la integració de la música i l'art amb la resta de la vida (Iturbe, 2006). Malgrat aquesta complementarietat, basant-nos en aquesta diferenciació i analitzant cada un dels diferents aspectes característics, podem concretar els objectius següents:

- Lassimilació i el desenvolupament d'aptituds tecnicoprofessionals des de l'àmbit de les classes de música. Aquest aspecte parteix de l’eix central de les colònies musicals, en el qual està implícit un aprenentatge i desenvolupament en aquest àmbit artístic. Per tant, els objectius musicals de les colònies són, en un primer moment, semblants als que es poden establir durant el curs lectiu si ens referim a l'aprenentatge musical. Aquests objectius es veuen modificats en la temporització, la qual podem anomenar d'exprés, que obliga, a més a més, a plantejar una elecció del repertori que suposi per a l’alumnat una proposta innovadora en comparació amb la del curs lectiu, tot i que requereix la mateixa pre-

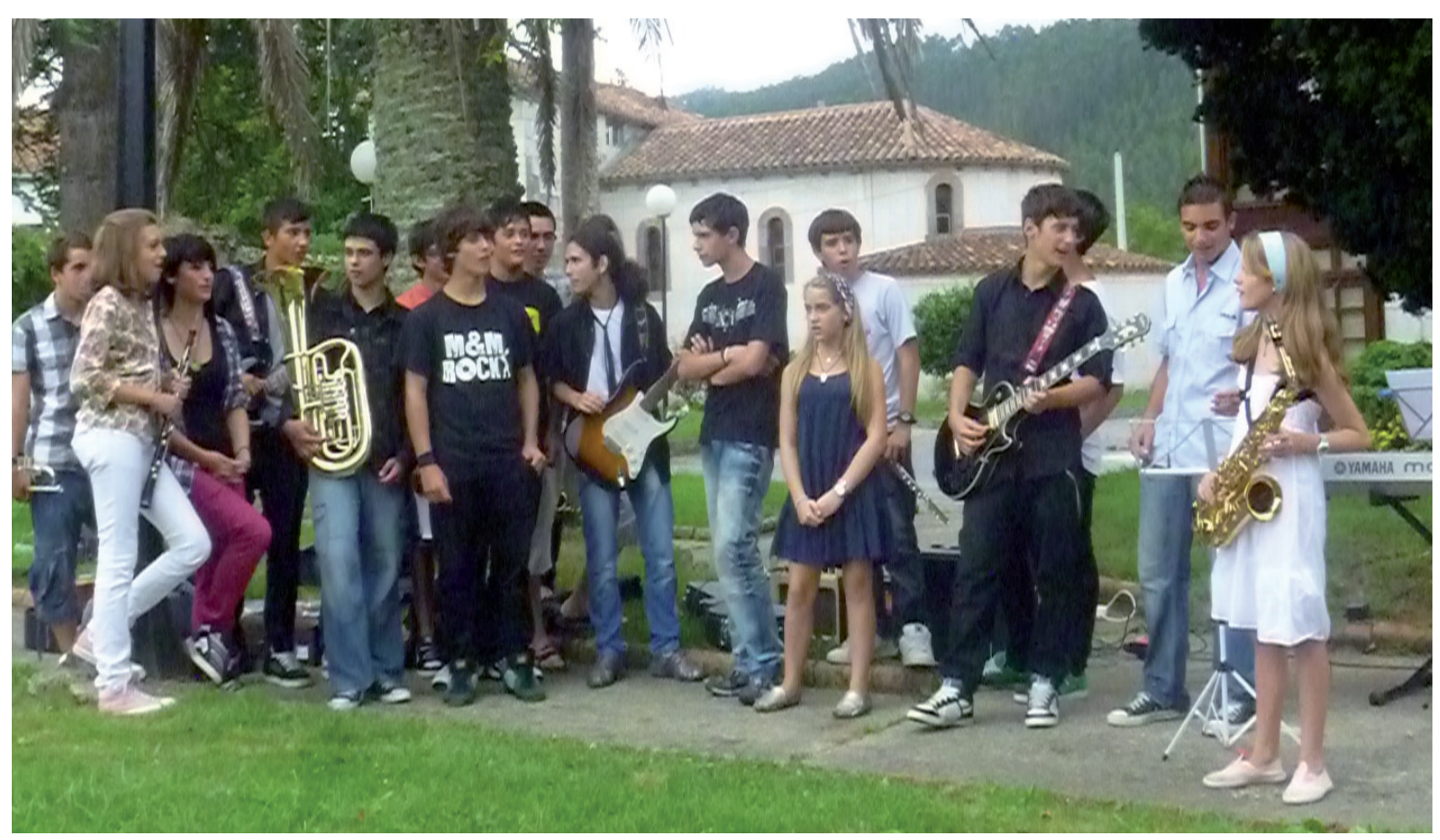


paració, equilibri i estructuració que la de una classe "normal" (Barniol, 2010). A més d'això, els horaris descrits de més de cinc hores de classe cada dia obliguen a un repertori que permeti adequar-se a les limitacions físiques de cada instrumentista. En qualsevol dels casos, els constrenyiments temporals impossibiliten l'assentament complet del fenomen artístic, per la qual cosa l'aprenentatge que es realitza en unes colònies no l'ha de pretendre.

D’altra banda, les mateixes característiques de classes collectives propicien el desenvolupament dels aspectes musicals que parteixen de la música en conjunt i la qual, atenent a la realitat de les escoles de música, no sempre està present. En aquest sentit, les colònies musicals suposen aquest suplement que Mills descriu quan manifesta que "idealment, magradaria que tots els estudiants d'instrument tinguessin una barreja de classes de grup i individuals, una combinació que s'ajustés en cada moment a les seves necessitats" (2007: 141).

D'altra banda, si ens centrem en l'estreta relació existent entre la motivació acadèmica i la percepció que l'alumnat tingui del professorat (Arriaga Sanz, 2006), les colònies musicals resulten un espai singular on aquesta percepció està vinculada a la convivència i permeten establir unes relacions personals que afavoriran aquesta motivació.

- Lassimilació i el desenvolupament d'aptituds tecnicoprofessionals des de làmbit de les activitats guiades de temps lliure. Aquest desenvolupament no està present més que en activitats esporàdiques en les quals es treballa l'expressió artística o l'expressió corporal. Tot i això, i tenint en compte la transversalitat de les competències, el reforç d'algunes d'aquestes serà beneficiós si ens centrem en els resultats musicals. Així, per exemple, un desenvolupament de la creativitat des de l'àmbit del lleure tindrà la seva repercussió en les aptituds tecnicoprofessionals. D'aquesta manera, i com que l'espai de les colònies és procliu al desenvolupament de la creativitat (Calderón, 2013), podem considerar que la creativitat musical també es veurà reforçada.
- Lassimilació i desenvolupament de competències personals i socials des de làmbit de les classes de música. El desenvolupament en la personalitat que s'aconsegueix a través de la música ja s'ha tractat en moltes ocasions, per la qual cosa nomes reflectirem aspectes estretament vinculats amb les colònies musicals, com la característica de classes col-lectives a què hem fet referència en aquest mateix apartat. Compartim les paraules de Gustems, Gale i Gimeno quan fan una reflexió sobre els valors que aporta la pràctica musical col-lectiva:

Més enllà dels valors que aporten i desenvolupen
les activitats musicals individuals (constància, es-
forç, concentració, audició atenta, precisió, memò-
ria, curiositat, respecte, interès, sensibilitat, creati-
vitat, espontaneïtat, esperit lúdic, etc.), la pràctica
col-lectiva de la música potencia especialment al-
tres valors molt preuats per a la integració social
de les persones: el treball en equip, el respecte, la
confiança, el compromís, la responsabilitat, la flexi-
bilitat, la paciència, la participació, la comunicació,
lentusiasme, la llibertat i la igualtat, per esmentar
els principals (2009: 12).

- L'assimilació i desenvolupament d'actituds personals i socials des de l'àmbit de les activitats guiades de temps lliure. Tot el desenvolupament que es produeix des d'aquest àmbit és comú en totes les colònies, independentment de la tipologia que sigui, basant-se en un desenvolupament de valors que es desprenen de l'adaptació a un nou espai social i físic, l'autonomia i independència en separar els menors del seu àmbit familiar, l'esforç físic i mental a involucrar-se en una contínua realització d'activitats tant musicals com d'oci, la sociabilitat que es desenvolupa des de la convivència amb nous companys, etc. En qualsevol cas, i tal com hem descrit anteriorment, totes aquestes competències reforçades des del lleure tindran el seu reflex en làmbit artístic.

Si bé tot el que s'ha mostrat fins ara pot identificar-se com a individualitats, en les colònies musicals la complementarietat entre classes i lleure fa que tots ells es complementin i alhora es condicionin, ja que sense un no existiria cap dels altres. 


\section{Conclusió}

Tal com hem descrit en aquest article, les colònies musicals són una proposta educativa arrelada a Catalunya que difereix de qualsevol altra activitat musical. Els seus beneficis es basen en el desenvolupament de múltiples competències, tant artístiques com personals i socials. D’aquesta manera, la combinació de música, temps lliure, lleure, activitats d'oci, assajos, companys, allunyament de la llar i una infinitat de característiques, fan d'aquesta experiència educativa una sòlida experiència vivencial.

\section{Bibliografia}

Arriaga Sanz, C. (2006). "Importancia de los condicionantes contextuales en la educación musical". Música y educación, 68, 131-140.

BARNiol, E. (2010) "La sessió de música a l'escola. Orientacions didàctiques i consideracions metodològiques per al seu plantejament". Comunicació Educativa, 23, 29-33.

Bisquerra Alzina, R. i Pérez Escoda, N. (2007). "Las competencias emocionales." Educación XXI, 10, 61-82.

Calderón Garrido, D. (2013). "Ocio y música para jóvenes: una educación creativa”. Dins J. Gustems (ed). Creatividad y Educación musi- cal: actualizaciones y contextos (pp. 101-110). Barcelona: DINSIC.

Calderón Garrido, D. (2015). Las colonias musicales en España: Historia y dimensiones formativas. Barcelona: Universitat de Barcelona.

Calderón Garrido, D.; Gustems CarniCer, J., i Calderón Garrido, C. (2014). "Colonias musicales: análisis y objetivos didácticos"Música y Educación, 98, 32-38.

Calderón Garrido, D.; Gustems Carnicer, J., i Calderón Garrido, C. (2015). "Les colònies musicals: una proposta educativa des de Catalunya". Educació i Historia. Revista d'Història de l'Educació, 26, 145-160.

Gustems CARnicer, J. (2007). Aproximación metodológica a la didáctica de los instrumentos musicales. Apuntes para un curso de doctorado. Barcelona: Recercat.

Gustems, J.; Gale, R., i Gimeno, P. (2009). "Música i acció comunitaria, un territori que cal conquerir". GUIX. Elements d'Acció educativa, 360, 11-14.

Iturbe, B. (2006). “Campamento musical”. $P a$ dres y Maestros, 301, 23-26.

Mills, J. (2007). Instrumental teaching. Oxford: Oxford University Press.

Palacios, F. (1995). "Música de verano". Eufonía, Didáctica de la música, 1, 117-129. 